\title{
Application of Case Method in Organic Chemistry Teaching of Pharmacy $^{*}$
}

\author{
Jianbo ZHOU, Shuai ZOU, Chao XU, Xiaoying CUI, Ming ZENG \\ Wen CHEN*
}

Department of Basic Medicine, Changsha Medical University, Hunan, Changsha 410219

*Corresponding Author: chenwen0520@qq.com

Keywords: Case method; Pharmacy; Organic Chemistry; Questionnaire Survey

\begin{abstract}
This article finds that traditional teaching methods cannot catch up with the pace of times and cannot meet the students' needs through questionnaire survey, carries out case method teaching reform in organic chemistry of pharmacy, introduces the origin and concept of the case method, and meanwhile expounds the essential conditions for smoothly implementing the case method. It presents the specific application of the case method in the organic chemistry course in pharmacy of Changsha Medical University.
\end{abstract}

\section{Introduction}

Modern clinical medicine includes synthetic drugs and natural drugs, more than $90 \%$ of which are organic compounds, so organic chemistry is an important professional basic course in medicine and pharmacy. Organic chemistry is an experimental subject for learning the composition, structure, nature and change law of organic compounds. Pharmacy students not only shall predict the nature of drugs, pharmacodynamical mechanism, etc., but also shall be engaged in new drug research and development in the future, which requires them to more enrich their knowledge about organic chemistry and basic skills. But the performance of medicine and pharmacy students of our university in recent years has not reached the above requirements: the students' exam scores are not high and the pass rate is extremely low. Even students with good performance in exams have poor operational ability. In recent years, our students' performance in provincial- or state-level chemical games has been unsatisfactory.

Before 2014, the organic chemistry teaching of medicine and pharmacy of our university mainly focused on the teaching by teachers, and the students passively accepted the traditional teaching methods. In order to get the opinions and suggestions of students on the existing teaching mode, I carried out a questionnaire survey of organic chemistry learning willingness, learning interest, learning methods and learning disabilities of 218 medicine and pharmacy of Grade 2014, and the result is as follows:

\begin{tabular}{|c|c|c|c|}
\hline $\begin{array}{c}\text { Survey } \\
\text { Contents }\end{array}$ & \multicolumn{3}{|c|}{ Survey Result } \\
\hline \multirow{2}{*}{$\begin{array}{c}\text { Learning } \\
\text { willingness }\end{array}$} & High & Average & Weak \\
\cline { 2 - 4 } & 190 persons $(85.16 \%)$ & 15 persons $(6.89 \%)$ & $\begin{array}{c}3 \text { persons } \\
(1.38 \%)\end{array}$ \\
\hline \multirow{2}{*}{$\begin{array}{c}\text { Learning } \\
\text { interest }\end{array}$} & High & Average & Weak \\
\cline { 2 - 4 } & 100 persons $(50.46 \%)$ & $\begin{array}{c}32 \text { persons } \\
(14.68 \%)\end{array}$ & $\begin{array}{c}86 \text { persons } \\
(39.45 \%)\end{array}$ \\
\hline
\end{tabular}




\begin{tabular}{|c|c|c|c|}
\hline \multirow{2}{*}{$\begin{array}{l}\text { Evaluation to } \\
\text { organic } \\
\text { chemistry } \\
\text { class }\end{array}$} & Lively and interesting & No feeling & Dull \\
\hline & 85 persons $(38.99 \%)$ & $\begin{array}{l}62 \text { persons } \\
(28.44 \%)\end{array}$ & $\begin{array}{l}71 \text { persons } \\
(32.57 \%)\end{array}$ \\
\hline \multirow{2}{*}{$\begin{array}{l}\text { Final exam } \\
\text { performance }\end{array}$} & $100-80$ scores & $80-60$ scores & $<60$ scores \\
\hline & 38 persons $(17.43 \%)$ & $\begin{array}{c}110 \text { persons } \\
(50.46 \%)\end{array}$ & $\begin{array}{l}70 \text { persons } \\
(32.11 \%)\end{array}$ \\
\hline $\begin{array}{c}\text { Learning } \\
\text { methods and } \\
\text { disabilities }\end{array}$ & \multicolumn{3}{|c|}{$\begin{array}{l}70 \text { persons }(32.11 \%) \text { think organic chemistry is quite easy to } \\
\text { learn, and they have their own workable learning methods; } 81 \\
\text { persons }(36.70 \%) \text { feel chemistry is quite difficult to learn, } \\
\text { because it has a lot of knowledge points; but they think they can } \\
\text { barely understand it by making efforts; } 67 \text { (30.74\%) think } \\
\text { organic chemistry is extremely difficult to learn, cannot } \\
\text { understand it in class, and cannot finish the after-class exercises. }\end{array}$} \\
\hline
\end{tabular}

From the survey result we can see that, most students aware that organic chemistry is very important, and they want to learn it. However, due to the defects of traditional teaching methods, most students feel organic chemistry is dull, so the lose the learning interest, cannot find the appropriate learning methods, have some difficulties in learning, and their academic performance is poor. In order to improve the fun of the organic chemistry course, the students' learning interest and academic performance, I carry out a series of education and teaching reform activities in the organic chemistry teaching of Grade 2015 Pharmacy Class. The author implement discussion, case, question and other types of teaching methods, wherein the case method is deeply affected by the students and has achieved good result.

\section{Origin and connotation of case method}

As a question discussion method, the case method was first put forward by Socrates in Greek [1]. In 1870, it was introduced into Harvard University by legal scholar Professor Lang in 1870, was vigorously promoted in Law School and the School of Management, and formed the modern "case method". It ruled the whole university and immediately became popular in the world. Case method is a teaching method [2] whose base is science, materials are cases, means is a Socratic method and goal is "to link as a lawyer". That is to say, in the method, teacher shall first prepare a case, present a certain number of purposeful problems according to the teaching purpose and requirements, organize the investigation, thinking, analysis, discussion, exchange and other activities to the cases, and the students work out the answers of questions through such activities and the knowledge that they learn. Case teaching can improve the students' ability of analyzing and solving problems, and deepen their understanding to the basic concepts and principles.

\section{Specific implementation process of case method in our university}

\section{A.Eliminate two mistaken ideas of teachers and students}

1. Correctly distinguish example teaching and case teaching[3]. Examples in example teaching are carefully or improvisational prepared for the teacher to explain a knowledge point. Such examples can be made up by the teacher or true, only to deepen the students' understanding to some concept or principle. While cases in the case method are facts including questions or difficult situations. They are carefully prepared by the teaching but not made up, only to train the students' ability of analyzing and solving problems, promote the 
formation of the students' learning transfer ability, so that the students can solve an actual problem with a principle or concept.

2. Attach importance to theoretical teaching[4], and carry out case teaching. Never replace theoretical teaching with case teaching, because case teaching is only a bridge to connect theory and practice, and it can help the students to form the scientific world outlook "practice is the sole criterion for testing truth".

\section{B. Select cases suitable for case teaching}

Cares are the core of the case method. The selection of cases directly affects the effect of case teaching. Some of the cases adopted in the organic chemistry class of our university are cases[5] from "Organic Chemistry" edited by Yang Lu of Science Press, and other cases are collected by our teachers by referring to references and sorting out materials. They form the special case library of our teaching and researching section. These cases are mostly related to medicine, and reflect the cutting-edge knowledge and development of organic chemistry in all aspects. We put forward and solve problems according to the characteristics of cases, so as to highlight our teaching emphases.

\section{C.“'One tree does not make a forest”.}

We must not only use one teaching method in the organic chemistry teaching, but shall combine the case method with the discussion teaching method, question teaching method, heuristic teaching method and other teaching methods.

\section{D.Examples of our university for case teaching}

1.Physical properties of alkanes and alkenes

In the learning of physical properties of Chapter 2 Alkanes in organic chemistry, the author focuses on explaining that the boiling point of alkanes mainly depends on the molecular inter-atomic forces which include Van der Waals force and hydrogen bond, and the Van der Waals force is related to the molecular weight and molecular polarity. The melting point of a substance is not only related to the molecular interaction but also related to the molecular symmetry: the better the symmetry is and the tighter are molecules lined in the crystal lattice, the higher is the melting point. When mentioning the physical properties of Chapter 3 Olefin, the author does not explain the affecting factors of the boiling point and melting point of substances but directly presents the following cases:

Cis-2-butene b.p3. $5^{\circ} \mathrm{C}, \mathrm{m} . \mathrm{p}-139^{\circ} \mathrm{C}, \mu \quad 0.33 \mathrm{D}$; trans-2-butene b.p0. $9^{\circ} \mathrm{C}, \mathrm{m} . \mathrm{p}-106^{\circ} \mathrm{C}, \mu \quad 0$. Question: Why is the boiling point of a cis structure high but its melting point low?

Give the whole class 3 minutes to think and discuss, then ask the students to answer according to the basic knowledge that they learn (about 5 minutes), and finally the teacher summarizes the view points of all the students: Cis-2-butene and trans-2-butene are isomeride, the boiling points of the substances depend on molecular polarity: the polarity of cis-2-butene is greater than that of trans-2-butene, so the boiling point of cis-2-butene is higher than that of trans-2-butene; while melting point is not only related to the molecular inter-atomic forces but also related to the molecular symmetry, the symmetry of trans-2-butene is high, so its melting point is also high.

Through this case, the students further understand the affecting factors of the boiling point and melting point, and learn how to solve actual problems with the basic knowledge that they learn.

2. Chemical properties of conjugated dienes and aromatic hydrocarbon

First, focus on introducing the structural characteristics and chemical properties of conjugated dienes and aromatic hydrocarbon in Chapters 4 and 5, and then introduce the structure and nature cases of ferrocene in order to further consolidate the knowledge about aromaticity after explaining Chapter 5: 


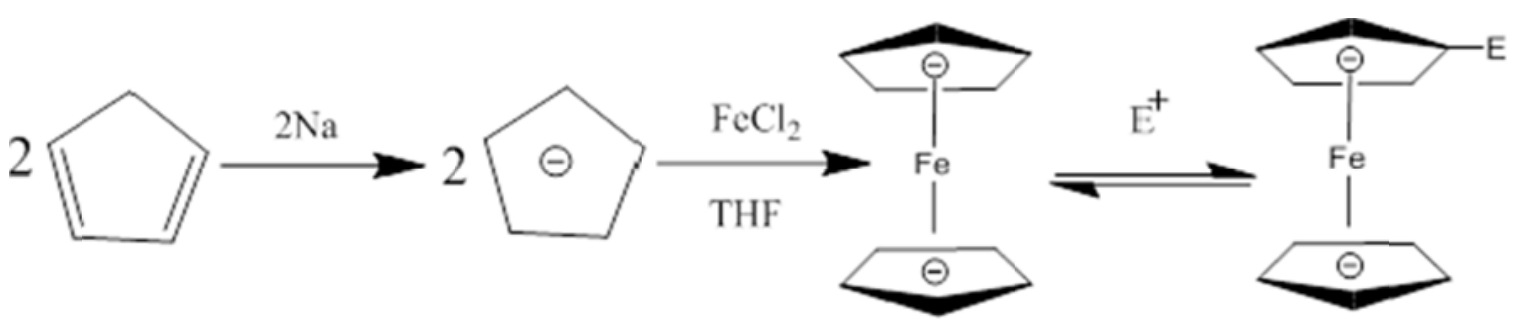

Question: Why is cyclopentadiene conjugated diene and can form a compound with Fe? Why electrophilic substitution reaction can take place but catalytic hydrogenation and Diels Alder reaction cannot take place on a cyclopentadiene ring after ferrocene?

Give the students 6 minutes to think and discuss freely, then remind them to memorize the structural characteristics and Hückel Rule. Under the teacher's guidance, the students actively put forward their opinions (about 7 minutes), and the teacher summarizes as follows according to the students' answers: Cyclopentadiene is acid, forms a cyclopentadiene fragrant anion after reacting with sodium metal, and provides a pair of electrons so as to form the coordinate bond with $\mathrm{Fe}$; in addition, cyclopentadiene negative ions have aromaticity, so it can have electrophilic substitution reaction but cannot have the characteristic reaction of conjugated diene.

Through this case, the students have more comprehensive mastery to the structure and nature of conjugated dienes and aromatic hydrocarbon. And the case plays an active role in promoting the students' ability of analyzing and solving problems as well as learning transfer ability.

\section{Conclusion}

The above two cases are only two representatives in our case teaching. We use 1 to 2 cases in each chapter of the Grade 2014 organic chemistry teaching. The case teaching method arouses the class atmosphere, improves the students' learning ability and inspires the students' learning enthusiasm. Through this method, the students' academic performance is generally improved: the pass rate of organic chemistry in Grade 2014 pharmacy reaches $85.16 \%$. The author thinks case method is a teaching method suitable for organic chemistry teaching, helps to improve the teaching quality and teaching level, and is worthy of promotion in organic chemistry teaching.

\section{Acknowledgements}

Fund Projects: Natural Science Funded by Education Department of Hunan Province (No:13C1127).

\section{References}

[1] Youping Tang,Shuguang Zhou. Research on Application of Case Method [J]. Journal of Sichuan College of Education, 2010,26(1):27-30

[2] Zhenghui Li. Critical Process and Enlightenment of American Case Method [J]. Law Review of Nanjing University, 2012 Autumn Volume,337-358.

[3] Bolan Zhong, Zhifeng Cui. Eliminate Mistaken Ideas of Case Teaching [J]. Vocational Education Research,2008,5:126

[4] Jianguo Wu. Several Problems About Case Method [J]. Journal of Xinzhou Teachers University,2004,20(4):79-82

[5] Yang Lu.Qingeng Li. Organic Chemistry[M]. Science Press, 2010.9 